\title{
Selection of Tree History Management System Items for Analyzing the Causes of Landscape Tree Defects in an Apartment Complex
}

\author{
Sang Wook Park ${ }^{*}$ \\ Deputy general manager, Department of Landscape Architecture, Hyundai Engineering \& Construction, Seoul 03058, Korea
}

\section{ABSTRACT}

Background and objective: It is difficult to conclusively determine the exact cause of tree defects since multiple causes are involved such as climate change, plantation, tree quality and planting time, construction, planting base, drainage, sunshine conditions, maintenance, and microclimate. The data related to landscaping construction defects are scattered or fragmented by companies and years, but not managed systematically by the defect information management system. Most of the earlier studies associated with tree defects in apartment complexes suggested defect rates after examining tree defects in the completed construction site and proposed fragmentary and subjective conclusions about the causes of defects observed in trees with high defect rates. It is proposed to continue to conduct studies on the establishment and analysis of systematic databases to identify the exact causes of tree defects and measures to improve, and the need to accumulate systematic data in the construction process where many defects arises. This study was conducted to reduce the defects of trees planted in apartment complexes.

Methods: Main factors related to tree defects were subdivided based on the results of literature review and a defect investigation at the completion site, and tree history management items were selected and subdivided during the construction stage.

Results: The criteria for the preparation of subdivided items were obtained, and the tree history management checklist was written for the site under actual construction and a systematic database was established. Items that are categorized based to the causes of defects include the location of nurseries, date, tree quality, site conditions, planting techniques, microclimates, and maintenance.

Conclusion: This study suggested tree history management items based on the tree defects that can be identified at the construction stage and applied them to the selected study site, which differentiates this study from earlier studies. It will be necessary to conduct a comprehensive and objective time series analysis on tree defects that occur over time by continuously monitoring and collecting data after construction.

Keywords: life cycle, maintenance, microclimate

\section{Introduction}

\section{Necessity of research}

Recently, landscape spaces in apartment complexes have been differentiated to improve the brand value of construction companies and customer satisfaction. The size of facilities has increased and high-end finishing materials and objects have been increasingly utilized. The types of trees planted in outdoor spaces have been differentiated and the density of plants has also extremely increased with the aim of providing finished plants upon the completion of apartment complexes. Most of the planting sites in apartment complexes are artificial ground where large-sized trees are planted through structural analysis. To meet the trends in differentiated landscape and reduce complaints from and cost for repairing tree defects, measures to categorize and

Received: April 28, 2020, Revised: May 14, 2020, Accepted: June 4, 2020

First author: Sang Wook Park, psw04@hdec.co.kr, (D) https://orcid.org/0000-0001-9061-7642

*Corresponding author: Sang Wook Park, psw04@hdec.co.kr, (i) https://orcid.org/0000-0001-9061-7642 
address tree defects have been researched and applied to construction sites, but it has been difficult to analyze tree defects that are caused by the combination of multiple factors in depth due to the lack of data across the life cycle of trees at the stage of construction. According to the recent report released by the Korea Land and Housing Corporation, the rate of tall tree defects in apartment complexes has decreased (recently $10.9 \%$ ), but the rate of tree defects is still high over $10 \%$ (Yoon et al., 2017).

Withered trees can be attributed to the combination of multiple causes including climate change, plantation, quality of plants, planting timing, construction techniques, planting base, drainage, sunshine conditions, wind environment and maintenance. In particular, data related to landscape construction defects are separately managed by company and year and have not been systematically managed through a system for managing data on defects.

To objectively analyze the causes of defects of trees planted in green spaces in apartment complexes, it is very important to accumulate data through the management of tree history at the stage of construction. In particular, basic research should be conducted to select items for the management of tree history and accumulate data, which is essential for analyzing the causes of the increasing number of tree defects and reducing the rate of defects.

\section{Trends in related studies}

As trees can be withered by the combination of multiple causes, efforts have been continuously made to reduce symptoms observed in withered trees and thus to reduce tree defects at the stage of maintaining tree defects, though it is difficult to identify the exact cause of tree defects. Efforts to reduce tree defects in apartment complexes over the past decade have been mostly focused on planting base and maintenance. To reduce the number of withered trees caused by poor drainage, drainage boards used in the method of subsurface drainage were replaced by the aggregate layer placed over the entire surface, and the capacity of collecting wells for surface drainage was quantified as the capacity per unit area. The main agent of bringing landscape soil into construction sites was originally the department of civil engineering but now is that of landscape architecture and the standard for the landscape soil that is brought into construction sites and the process of checking its quality were strengthened. The budget for maintenance during the period for warranty liability for defects is set aside when signing construction contracts to ensure maintenance is done by constructors (Table 1).

Among studies on the reduction of defects in landscape trees, Kim (2018) reported that the causes of landscape tree defects occur most frequently in the process of planting, and divided the causes of defects into the types of planting construction. It was argued that studies need to be conducted more specifically and based on science and suggested to computerize and utilize the content of operations and on-site conditions. Kim (2018) also suggested to include in the computerized data items like the conditions of construction sites, where and when trees were purchased, the quantity of trees and all the information related to planting and to utilize the computerized data in similar construction sites in order to reduce the tree defects that are repeatedly observed in construction sites. Kim (2014) surveyed and analyzed the effects of changes in

Table 1. Major improvements to reduce tree defects

\begin{tabular}{cccc}
\hline \multicolumn{2}{c}{ Division } & Before improvement & After improvement \\
\hline \multirow{2}{*}{ Drainage facility } & $\begin{array}{c}\text { Underground } \\
\text { Ground }\end{array}$ & Drain board and perforated plastics pipes & Gravel stratum(thk. 20cm) and roof drain \\
Soil & Main agent & No standard & 1 ea/330 $\mathrm{m}^{2}$ \\
& Test & Civil engineering & Landscape architecture \\
Maintenance & Cost & - & Soil analysis, permeability test \\
& Management & - & Budget for maintenance expenses \\
& Management office & Management office, constructor \\
\hline
\end{tabular}

Note. Adapted from “A preliminary study on the planting condition improvement by climate changes”, by E.J. Yoon et al., 2017, Land and Housing Institute, Daejeon, Korea. 
the landscape of apartment complexes on landscape plants and tree defects and suggested the causes of tree defects and ways to improve by dividing the causes into 5 items including rapid climate change, poorly selected trees, poor planting base, poor construction management and poor maintenance. It was also pointed out that defects are caused by the combination of multiple factors over the long period of time due to the characteristics of landscape construction and thus that databases need to be continuously established and analyzed in a systematic way in order to identify the exact causes of defects and to come up with measures to improve. Kim (2006) surveyed and analyzed the status of defects observed in landscape trees in apartment complexes in Seoul and suggested 7 measures to improve the status. Kim (2006) perceived that surveying the quantity of planted landscape trees and the number of trees with defects in a certain location is not enough to survey and analyze the causes of defects and to suggest measures to improve the status and suggested to plant trees of the same species in $\mathrm{A}, \mathrm{B}$ and $\mathrm{C}$ places and to monitor how they react to their surrounding conditions or environment and the methods and timing of planting in order to survey and analyze the causes of defects. Lim and Kim (2001) surveyed and analyzed the rate of defects of landscape trees by property and by tree height in 50 apartment complexes developed by the private sector in Daegu and Gyeongbuk Province with the aim of proving base information required for landscape construction in apartment complexes in the future. Since the study targeted broad areas and their capacity to manage the environment of planting base and the timing of recognizing defects differed, it was difficult to exactly identify the causes of defects.

Among studies on systems for managing trees, Kim et al. (2007) developed a program to monitor the status of trees planted in a campus at a glance, and ensured that information on the area of management, the number of management, the name of trees, the family an scientific name of trees, properties, size, growth conditions, images of trees, the unit price of trees, etc. can be recorded in the section of managing basic information on trees. Jung and Sim (2012) on the GPS/RFID-converged service and system of tree management for arboretums using smartphones and entered data on the number of management, the species of trees, age, height, rhizome, crown width, the existence of diseases, images of trees, the date of transplanting, the name of groups, the name of managers, etc. Yoon et al. (2017) mentioned the necessity of establishing a systematic base for management such as establishing a database of attributes for monitoring responses to climate change by tree species and the database was divided into the name of trees, the properties of trees, the location of planting, the depth of soil, resistance, risk factors, habitats, and present and future climate suitability.

Most of the earlier studies on tree defects in apartment complexes surveyed tree defects after the completion of buildings, and suggested fragmentary and subjective conclusions on the causes of trees with a high rate of defects only. They suggested to continue to conduct studies on the establishment and analysis of systematic databases in order to identify the exact causes of tree defects and establish measures to improve, and the need for the systematic accumulation of data in the process of construction where many defects arises.

\section{Research Methods}

Literature review and surveys on defects in sites where construction was completed were conducted to identify the main causes of tree defects, and items for managing the history of trees that can be recorded in the process of construction were selected and fragmented. The standards for writing the segmented items were established and the tree history management items were applied to a construction site to establish a systematic database.

\section{Selection of study site}

The study site was selected among those located in the central region of Korea where reconstruction projects are actively carried out. Apartment complexes where planting tall trees was completed between March 12 and May 20, suitable for planting and that was constructed in a flatland where the techniques of planting trees and daylight conditions were clearly observed were surveyed and the one that adopted a widely-used L-shaped layout (flat type + 
Table 2. Information of study site.

\begin{tabular}{lcccccccc}
\hline \multirow{2}{*}{ Division } & Location & $\begin{array}{c}\text { Completion } \\
\text { date }\end{array}$ & $\begin{array}{c}\text { Natural } \\
\text { ground } \\
(\%)\end{array}$ & $\begin{array}{c}\text { Landscape } \\
\text { area } \\
(\%)\end{array}$ & $\begin{array}{c}\text { Site } \\
\text { area } \\
\left(\mathrm{m}^{2}\right)\end{array}$ & $\begin{array}{c}\text { Dwelling } \\
\text { units } \\
(\text { no. })\end{array}$ & $\begin{array}{c}\text { Type } \\
\text { Form }\end{array}$ \\
\hline Study site & Hanam-si, Gyeonggi-do & October, 2020 & 22.0 & 43.7 & 44,521 & 932 & L type & Flat \\
\hline
\end{tabular}

tower type) was selected. In particular, the apartment complex created in a housing development district that shows little changes in the surrounding environment was targeted for the continuity of research. The selected study site is an apartment complex of 932 households located in Hanam-si and the site is located in the central northern region in terms of planting regions (Table 2).

\section{Categorization of the causes of tree defects through literature review}

Based on the results of literature review and the interview of constructors, the main causes of tree defects were divided into design, construction and maintenance stages. The stage of construction can be subdivided into digging, transporting, planting and maintenance, and the causes of defects associated with digging included poorly developed roots due to excessive fertilization, lack of climate suitability due to the discrepancy between planting regions, roots that were poorly cut and chemically treated, the non-application of antitranspirants and leaving trees on the ground after digging. The causes of defects associated with the discrepancies between the regions of production and planting were categorized based on the location of nurseries, and the causes of defects associated with maintenance at the stage of digging were categorized into tree quality as they seemed to be identified by checking the conditions of roots when trees were transferred into construction sites. The causes of defects that might occur at the stage of transporting included roots damaged by double stacking, dryness caused by not applying covers and not planting on the date of transporting trees into construction sites. Root damage was categorized into tree quality, and not planting on the date was categorized into transportation and planting date. The causes of defects that may occur during planting included not securing a sufficient depth of soil for planting, poor drainage due to the lack of drainage facilities, poor drainage due to natural soil, untimely planting, reconstruction, cementation due to the trampling effect of soil, immature fertilizers, deep-planted roots due to soil covering, separation of trees and roots, separation of roots and soil, trees planted in permanently shaded areas, pest outbreak due to poor ventilation and poorly strapped wood poles in windy areas. The causes related to soil depth and soil were categorized into planting base conditions, and those related to untimely planting and reconstruction were categorized into transportation and planting date. The causes related to separation of roots from trees and soil were categorized into tree quality, and those related to deep-planted roots due to soil covering were categorized into planting technique. Those related to trees planted in permanently shaded areas, ventilation and wind speed were categorized into microclimate. The causes of defects that may occur at the stage of maintenance included insufficient watering and poorly strapped wood poles, excessive dryness and moisture, and pest outbreak by weakening and poor ventilation. Those related to watering, fertilization and pest control were categorized into maintenance (Table 3).

\section{Selection of tree history management items}

The types of tree defects that can be managed at the stage of construction were segmented to select items of tree history management. Among the factors that commonly affect planted trees, subsurface and surface water drainage facilities were not set as a separate item as they already have standards regarding this. In subsurface facilities, a $20 \mathrm{~cm}$-thick aggregate layer was placed over the entire surface, and a vertical drain was installed at the interval of $20 \mathrm{~m}$ (radius). Surface drainage basically used the drainage facilities installed on the pavement, and collecting wells $\left(1 \mathrm{unit} / 300 \mathrm{~m}^{2}\right)$ were installed on green spaces. Based on the results of literature review, categorized items were selected for tree history management. 
Table 3. Main factors and categorization of tree defects

\begin{tabular}{|c|c|c|c|}
\hline Division & Classification & Details & Categorization \\
\hline Design & $\begin{array}{c}\text { Inappropriate } \\
\text { trees }\end{array}$ & $\begin{array}{l}\text { - Selection of species with weak portability } \\
\text { - Planting design without considering planting depth } \\
\text { - Insufficient consideration of growth environment }\end{array}$ & $\begin{array}{l}\text { Tree type } \\
\text { Size } \\
\text { Microclimate }\end{array}$ \\
\hline & Excavation & $\begin{array}{l}\text { - Weak root development and overgrowth due to excessive fertilization } \\
\text { - Lack of adaptability to climate due to differences in planting area } \\
\text { - Inadequate work before excavation and inadequate chemical treatment } \\
\text { - Untreated inhibitor } \\
\text { - After excavation, left in a collapsed state }\end{array}$ & $\begin{array}{l}\text { Tree quality } \\
\text { Location of nursery } \\
\text { Tree quality } \\
\text { Tree quality } \\
\text { Tree quality }\end{array}$ \\
\hline & Transportation & $\begin{array}{l}\text { - Root powder damage due to double loading } \\
\text { - Dry damage caused by not installing the cover } \\
\text { - Next day planting }\end{array}$ & $\begin{array}{l}\text { Tree quality } \\
\text { Tree quality } \\
\text { Date }\end{array}$ \\
\hline Construction & Planting & $\begin{array}{l}\text { - Insufficient soil depth } \\
\text { - Poor drainage due to lack of drainage facilities } \\
\text { - Natural ground poor drainage } \\
\text { - Untimely planting } \\
\text { - Reconstruction due to damage } \\
\text { - Soil consolidation by pressure } \\
\text { - Immature fertilizer } \\
\text { - Deep planting by fill soil } \\
\text { - Separation of trees and roots } \\
\text { - roots are not in close contact with the soil due to poor watering after planting } \\
\text { - Planted in permanent shaded area } \\
\text { - Pest outbreak by poor ventilation } \\
\text { - Insufficient stake in strong wind speed area }\end{array}$ & $\begin{array}{l}\text { Site condition } \\
\text { Maintenance } \\
\text { Site condition } \\
\text { Date } \\
\text { Date } \\
\text { Site condition } \\
\text { Maintenance } \\
\text { Planting technique } \\
\text { Tree quality } \\
\text { Maintenance } \\
\text { Microclimate } \\
\text { Microclimate } \\
\text { Microclimate }\end{array}$ \\
\hline Maintenance & $\begin{array}{c}\text { Maintenance } \\
\text { during planting }\end{array}$ & $\begin{array}{l}\text { - Insufficient irrigation and stake after planting } \\
\text { - Damage caused by drought and rainy } \\
\text { - Pest outbreak by weakening } \\
\text { - Soil consolidation by pressure }\end{array}$ & $\begin{array}{l}\text { Maintenance } \\
\text { Maintenance } \\
\text { Maintenance } \\
\text { Maintenance }\end{array}$ \\
\hline
\end{tabular}

Note. Adapted from "A study on the reduction of the landscape tree flaws: Focusing on Gwangju Metropolitan City park and green area", by H.S. Kim, 2018, Master's thesis, Chonnam University, Gwangju, Korea.

\section{Location of nurseries}

Regarding the effects of the location of tree nurseries on defects, Kim (2014) and Kim (2006) pointed out that trees failed to adapt to sudden changes in the surrounding environment due to the discrepancy between the regions of production and planting and suggested to select trees grown in places as close as possible. However, most of tree nurseries are located in the southern region where climate conditions are suitable for nurseries and there are also practical problems in using trees only from the same planting region as construction sites. To accumulate base data for analyzing the correlation between the location of nurseries and tree defects, the location of nursery was selected as a tree history management item. The location was classi- fied based on the classification suggested by Yoon et al. (2017) in to central northern, central and southern regions, southern coast and Jeju, and the location of nurseries were marked.

\section{Tree quality}

Regarding the effects of the conditions of roots brought into construction sites after digging and transportation on tree defects, Kim (2018) and Kim (2006) argued that the cause of defects is the roots damaged due to the excessive stacking of trees for saving transportation costs. In the case of trees dug from wild environments where planting base is weak, the size of roots is often smaller than the standard size or the shape is flat. To accumulate base data for ana- 
lyzing the rate of defects according to the conditions of roots, tree quality was selected as a tree history management item, and was classified into high, medium and low grades according to the conditions of roots of trees that were brought into construction sites.

\section{Date of tree transportation and planting}

The results of literature review show that untimely planting was analyzed to be a main cause of withered trees and the standard landscape construction specification specifies the time of planting suitable for each planting region (Ministry of Land Infrastructure and Transport, 2016). Kim (2018) suggested that tree defects can be reduced by planting trees on the same day when trees were brought into construction sites. The trees brought in construction sites are officially planted in areas where they can be planted immediately and are temporarily planted in areas where they cannot be planted as previous processes are delayed and interference phenomena occur. The date of tree transportation and planting was selected as a tree history management item to accumulate base data for analyzing the correlation of tree defects with the timing of planting and planting on the day.

\section{Site conditions}

Green spaces created in apartment complexes can be divided into artificial bases and natural bases, and the growth conditions and death rate of trees planted on artificial bases and natural bases have been continuously researched (Cho, 2010). As drainage facilities in artificial bases and the quality of landscape soil have been improved, the rate of tree defects in natural bases has gradually increased compared to that in artificial bases. The quality of landscape soil for creating planting bases is assessed by specialized agencies before and after being brought into construction sites to determine whether the soil is used according to the soil assessment grades. Since planting bases are an element that directly affects the growth and death of trees, site conditions were selected as a tree history management item to accumulate base data for analyzing the correlation between planting bases and tree defects. Green spaces were divided into artificial bases and natural bases, and slopes were separately marked. The assessment of soil was commissioned to agencies specialized in soil analysis including the Korea Forestry Promotion Institute (KOFPI) and the Korea Environment and Water Works Institute (KEWI) before and after bringing trees into construction sites.

\section{Planting techniques}

To prevent tree defects caused by ponding, trees have been conventionally planted higher than the ground, but the number of construction sites that plant trees flat on the ground has increased to prevent dryness damage caused by climate change as drainage facilities and the quality of landscape soil have been improved. For the areas that need the sense of enclosure, soil was mounded to plant trees higher than the ground, and for the areas that need to be leveled, trees were planted flat on the ground. Deep-planted roots affect the growth of trees and are observed when planting was done prior to the construction of facilities and thus trees are planted lower than the level of boundary stones or when half the roots of trees dug from slopes in wild environments are deep-planted or when trees are subsided after being planted. To accumulate base data for analyzing the relation between planting techniques and tree defects, planting techniques were selected as a tree history management item. Planting techniques were divided into up, flat and down planting, and in the case of up and down planting techniques, differences between the ground level(GL) of surrounding green spaces and the diameter of roots were marked (Fig. 1).

\section{Microclimates}

Microclimates directly affect the growth and withering of trees, but only very few studies have been conducted on the effects of sunshine and wind environments on the growth and withering of trees. Kim (2014) suggested that tree defects can be reduced by analyzing growth environments and selecting suitable trees through microclimate analysis such as shade analysis. To accumulate base data for analyzing the relation between tree defects and microclimates such as sunshine duration and wind speed, microclimates were selected as a tree history management item. To calculate sunshine duration depending on the location 


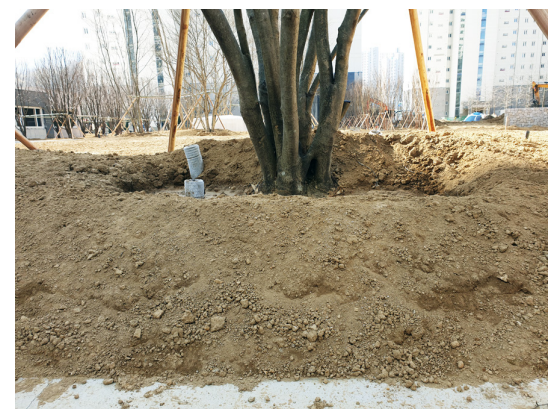

(A) Up

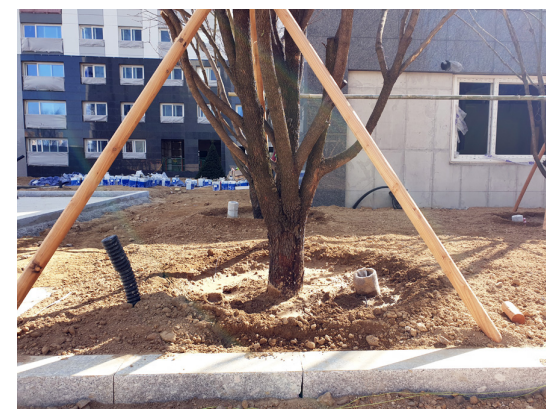

(B) Flat

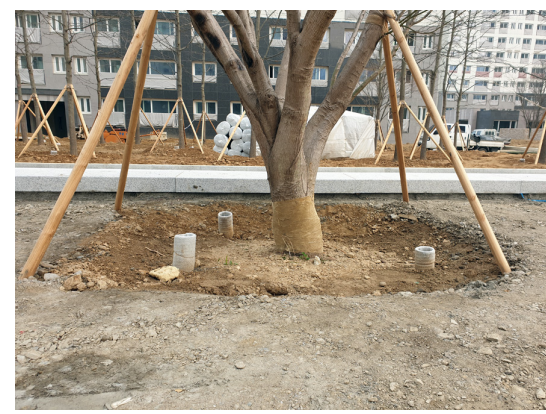

(C) Down

Fig. 1. Planting techniques for trees.

of the sun, the Solar Access Analysis of ECOTECT ANALYSIS (version 2011 for windows; Autodesk, San Rafael, California) was utilized. The weather data of the study site were obtained from the Korean Solar Energy Society that has accumulated reliable weather data for years. The daylight duration of the study site was analyzed as of the summer solstice (June 21) from 7 a.m. to 7 p.m. when the angle of daylight is maximized $\left(73.96^{\circ}\right)$. The size of cells for analysis was set as $2 \mathrm{~m} \times 2 \mathrm{~m}$ and mensuration was performed using AutoCAD to calculate the area of permanently shaded areas. Along with daylight environments, wind environments are also a main cause of withered trees. The roots of trees planted in places where the wind speed is strong are shaken, which can cause the withering of trees, and poor ventilation can also results in pest outbreaks. The direction and speed of the wind in outdoor spaces in apartment complexes are momentarily changed due to the effects of buildings, and thus it is difficult to collect accurate data (Park, 2019). Based on the results of literature review and the data collected by the Automatic Weather Station (AWS) in Seoul, certain points were selected in outdoor spaces (Fig. 2) and the wind speed was measured using a multifunction measuring instrument (KIMO INSTRUMENT AMI300).

\section{Maintenance}

Maintenance can be divided into maintenance during the period of construction after planting trees, and maintenance during the period of repair, and maintenance done by users after the period of repair. Kim (2014) and Kim (2006) highlighted the necessity of continuous maintenance after the

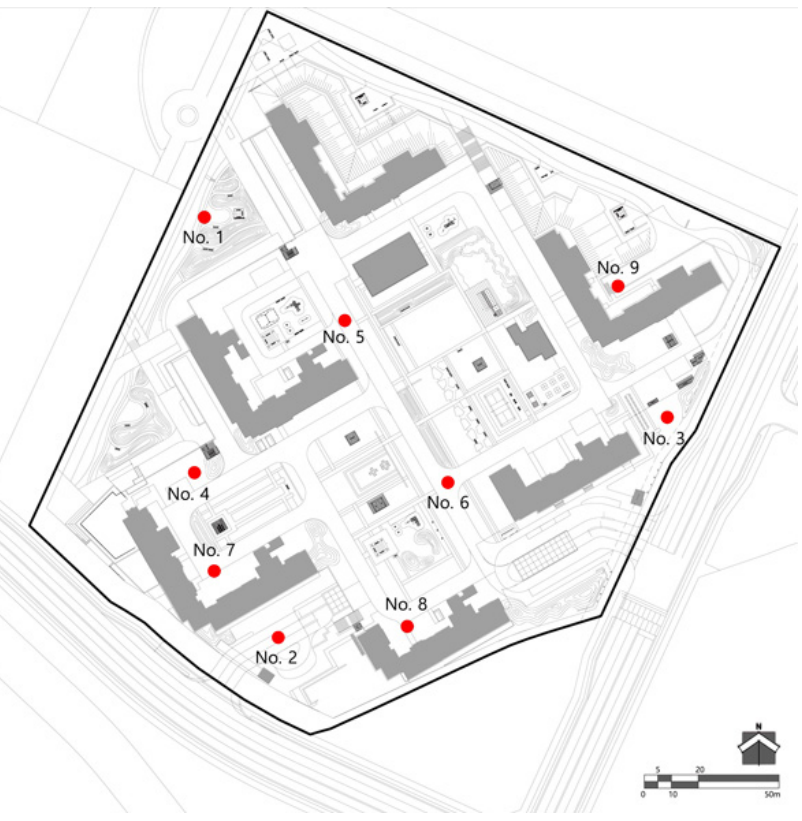

Fig. 2. Wind speed measurement points at study site.

completion of construction due to the defects caused by poor maintenance by residents. This study focused on the maintenance done during the period of construction. Since maintenance after planting trees is closely related to the growth and withering of trees and earlier studies reported that maintenance at the stage of construction is a main cause of withered trees, maintenance was selected as a tree history management item to accumulate base data for analyzing the relation between maintenance and tree defects. Maintenance items were divided into fertilization, watering and pest control, and the date of performance was marked. 


\section{Results and Discussion}

\section{Application of tree history management items}

The tree history management items selected above were applied to the study site that was under construction to collect base data for writing spatial and attribute data for a tree history management system.

\section{Location of nurseries}

The study site is located in the central northern region and the trees brought from Nursery $\mathrm{A}$ and $\mathrm{K}$ located in the same region include Pinus densiflora and Acer palmatum Thunb. The trees brought from Nursery B, C and J located in the central region include Malus prunifolia, Malus prunifolia, Quercus palustris, Prunus mume, Cornus kousa, Chionanthus retusus, Abies holophylla, Taxus cuspidata, Acer palmatum Thunb and Sorbus alnifolia, and the trees brought from Nursery D, E, F, H, I and L located in the southern region include Juniperus chinensis, Diospyros kaki, Lindera glauca, Cercidiphyllum japonicum, Stewartia pseudocamellia, Quercus palustris, Ilex macropoda, Metasequoia glyptostroboides, Lagerstroemia indica, Elaeagnus umbellata, Cornus kousa, Cornus offici- nalis, Salix chaenomeloides, Prunus yedoensis, Chionanthus retusus and Acer palmatum Thunb. The tree brought from Nursery G located in the southern coast was Celtis sinensis (Fig. 3).

\section{Tree quality}

The size of the roots of trees brought into the study site mostly met the standard size suggested by Lee (2004), 3-5 times the diameter of roots. All the roots were inspected and those damaged in the process of transportation and those of which roots were separated from the body were returned. No. 1-8 and 12-13 (Celtis sinensis) and No. 313-328 (Ilex macropoda) were dug from wild environments. No. 379-380 (Salix chaenomeloides) were collected among those that live in a wetland, and the size of their roots was 1.2 times the diameter of roots. No. 451-571 (Lindera glauca) were collected from wild environments and the size of roots was 2 times the diameter of roots. The conditions of roots were relatively poor.

\section{Date of tree transportation and planting}

Trees in the study site were planted from February 18 to May 29, 2020, and most of them were planted within

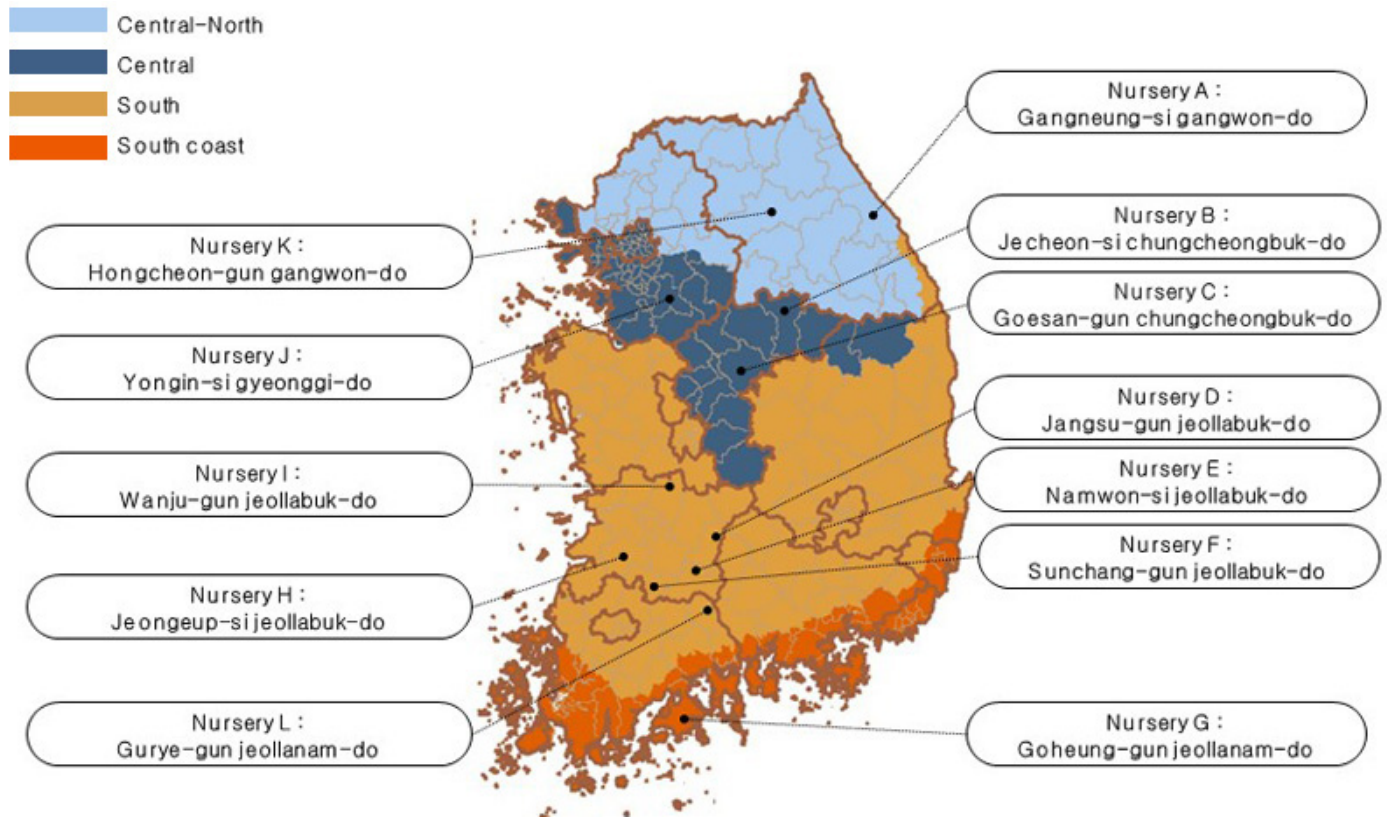

Fig. 3. Location of nurseries. Adapted from "A preliminary study on the planting condition improvement by climate changes", by E.J. Yoon et al., 2017, Land and Housing Institute, Daejeon, Korea. 
the period of planting suitable for the central region that was specified in the standard landscape construction specification (March 10-May 20). There was no untimely planting due to a delay in the previous process. Those of which date of transportation and planting differed including No. 103-111 (Lagerstroemia indica), No. 159-171 (Chionanthus retusus), No. 253-282 (Abies holophylla), No. 436-450 (Abies holophylla), No. 830-834 (Acer palmatum Thunb), and No. 1121-1193 (Abies holophylla), and they were temporarily planted before being officially planted due to a delay in the previous process. No. 4-6 (Celtis sinensis) and No. 331 (Zelkova serrata) were replanted due to changes in the conditions of the study site.

\section{Site conditions}

The soil brought into the study site was collected from four sites. Soil I, II, III and V were laid over the artificial base and Soil IV was laid over the natural base. The structure of the area where Soil $V$ was laid was checked and based on the result the landscape soil and artificial soil were mixed at the ratio of 50:50 to create a mixed planting base (Fig. 4).

The components of soil were compared and analyzed according to the soil assessment grades stated in the standard landscape construction specification. Soil I, II and IV were loamy sand and Soil III and V were sandy loam. The soil $\mathrm{pH}$ of Soil II was medium and that of Soil I, III, $\mathrm{N}$ and $\mathrm{V}$ was low. The content of organic matters of all types of soil was lower than the standard, and the total nitrogen of all types of soil was low. The content of effective phosphoric acid of Soil II and the base sub- stitution capacity of Soil III and V were analyzed to be low. The exchangeable cation of most types was medium or higher and the electrical conductivity and salinity of Soil II and IV were poor (Table 4). The low content of organic matters was improved with organic fertilizers, and the rest components were used as landscape soil without any improvement.

\section{Planting techniques}

As the design concept of the study site was flat landscape, trees were mostly planted flat on the ground. Over half of the roots of No. 1-8 and 12-13 (Celtis sinensis) and No. 313-328 (Ilex macropoda) that were collected

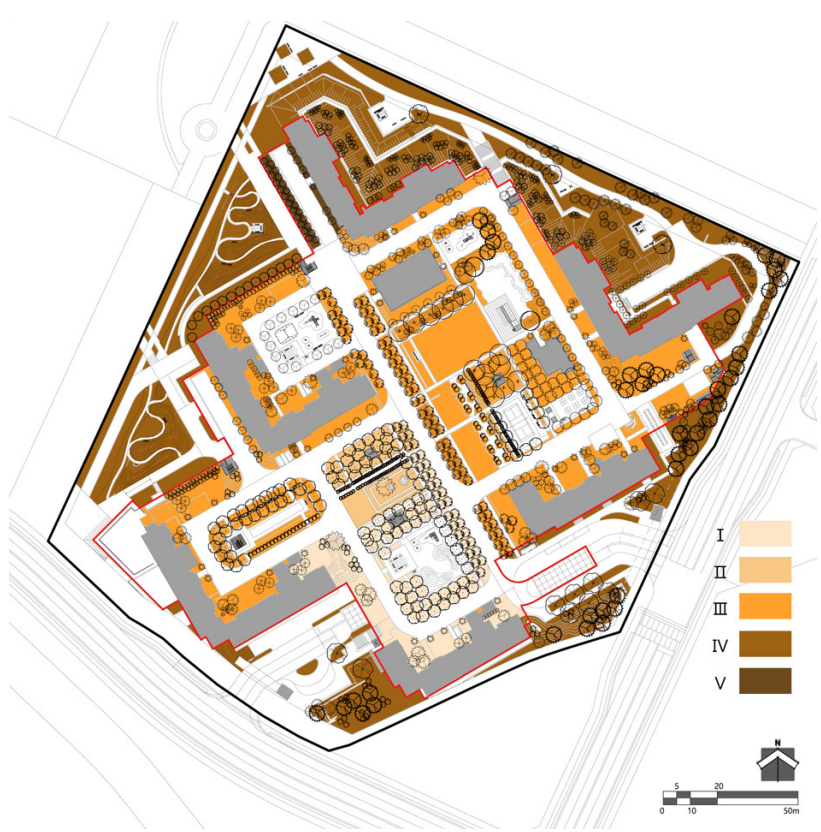

Fig. 4. Preparing ground with different types $(I-V)$ of soil.

Table 4. Comprehensive analysis of soil

\begin{tabular}{|c|c|c|c|c|c|c|c|c|c|c|c|c|c|c|}
\hline \multirow[b]{2}{*}{ Division } & \multicolumn{4}{|c|}{ Particle size analysis } & \multirow[b]{2}{*}{$\mathrm{pH}$} & \multirow{2}{*}{$\begin{array}{l}\mathrm{OM} \\
(\%)\end{array}$} & \multirow[b]{2}{*}{$\begin{array}{l}\mathrm{TN} \\
(\%)\end{array}$} & \multirow{2}{*}{$\begin{array}{l}\text { Available } \\
\mathrm{P}(\mathrm{mg} / \mathrm{kg})\end{array}$} & \multirow[b]{2}{*}{$\mathrm{CEC}$} & \multicolumn{3}{|c|}{ Exchangeable $(\mathrm{cmol} / \mathrm{kg})$} & \multirow[b]{2}{*}{$\mathrm{EC}$} & \multirow[b]{2}{*}{$\begin{array}{c}\mathrm{NaCl} \\
(\%)\end{array}$} \\
\hline & $\begin{array}{c}\text { Sand } \\
(\%)\end{array}$ & $\begin{array}{l}\text { Silt } \\
(\%)\end{array}$ & $\begin{array}{l}\text { Clay } \\
(\%)\end{array}$ & Texture $^{\mathrm{y}}$ & & & & & & $\mathrm{K}^{+}$ & $\mathrm{Ca}^{2+}$ & $\mathrm{Mg}^{2+}$ & & \\
\hline Standard & 85.0 & 15.0 & 10.0 & SL & $5.5-7.0$ & Above 3.0 & Above 0.06 & Above 100 & Above 6 & Above 0.6 & Above 2.5 & Above 0.6 & Under 1.0 & Under 0.2 \\
\hline I & 76.1 & 19.6 & 4.3 & LS & 7.2 & 0.01 & 0.029 & 130.3 & 8.17 & 0.22 & 5.89 & 2.63 & 0.15 & 0.002 \\
\hline II & 76.7 & 19.1 & 4.2 & LS & 5.0 & 0.01 & 0.029 & 65.4 & 7.49 & 0.21 & 6.83 & 4.93 & 7.65 & 0.377 \\
\hline III & 72.9 & 22.9 & 4.2 & SL & 7.2 & 0.01 & 0.031 & 209.7 & 5.74 & 0.16 & 5.73 & 1.16 & 0.13 & 0.002 \\
\hline IV & 80.5 & 15.5 & 4.0 & LS & 7.5 & 0.01 & 0.035 & 185.1 & 14.96 & 0.87 & 6.50 & 3.45 & 4.75 & 0.304 \\
\hline V & 72.9 & 22.9 & 4.2 & SL & 7.2 & 0.01 & 0.031 & 209.7 & 5.74 & 0.16 & 5.73 & 1.16 & 0.13 & 0.002 \\
\hline
\end{tabular}

Note. $\mathrm{OM}=$ organic matter; $\mathrm{TN}=$ total nitrogen $\mathrm{CEC}=$ cation exchange capacity $\mathrm{EC}=$ soil electrical conductivity.

${ }^{\mathrm{y}} \mathrm{SL}=$ Sandy Loam; LS = Loamy Sand. 
from slopes were planted using an up planting technique. No. 10 (Acer palmatum Thunb) and No. 283-312 (Diospyros kaki) were planted using a down planting technique. No. 742-745, 746-749 and 777-785 (Pinus densiflora) were planted after creating a mounding.

\section{Microclimates}

Based on the data of wind speed measured at selected points, the study site was divided into I - III sections. Section I is a natural base outside the apartment complex and is most seriously affected by the wind, and Lindera glauca, Stewartia pseudocamellia, Zelkova serrata, Metasequoia glyptostroboides, Chionanthus retusus and Celtis sinensis were planted in the section. Section II is an open space inside the apartment complex and is moderately affected by the wind, and Juniperus chinensis, Diospyros kaki, Cercidiphyllum japonicum, Malus prunifolia, Quercus palustris, Ilex macropoda, Lagerstroemia indica, Salix chaenomeloides, Prunus yedoensis, Abies holophylla, Taxus cuspidata, Acer palmatum Thunb and Sorbus alnifolia were planted in Section II. Section III is a permanently shaded area inside the apartment complex and is least affected by the wind as the section is surrounded by buildings. Cornus kousa, Chionanthus retusus, Taxus cuspidata and Acer palmatum Thunb were planted in the section (Table 5).

The daylight conditions of the study site were analyzed. Permanently shaded areas were mostly formed in the rear part of buildings that faced north and the surface area of the permanently shaded areas was $11 \%$ of the total area of green spaces. As the front part of buildings faced southeast or southwest, at least 5 hours of daylight were secured a day, which was analyzed to be good for the growth of trees. However, the spaces are not suitable for planting trees due to the designated spaces for inflatable air cushions in emergency, paved areas for pilotis and restrictions on planting trees for the lighting of low-rise residents (Fig. 5). In the permanently shaded areas, trees of which rate of defects is low such as Taxus cuspidata, Stewartia pseudocamellia, Chionanthus retusus and Acer palmatum Thunb were planted.

\section{Maintenance}

To minimize dryness damage, $100 \mathrm{ml}$ of a soil absorbent was sprinkled around the roots of tall trees of which root diameter was over $30 \mathrm{~cm}$. A water house was maintained around the roots for continuous watering, while planting tall trees. For those of which root diameter was over 15 $\mathrm{cm}$, at least two ventilation pipes were installed. Water was

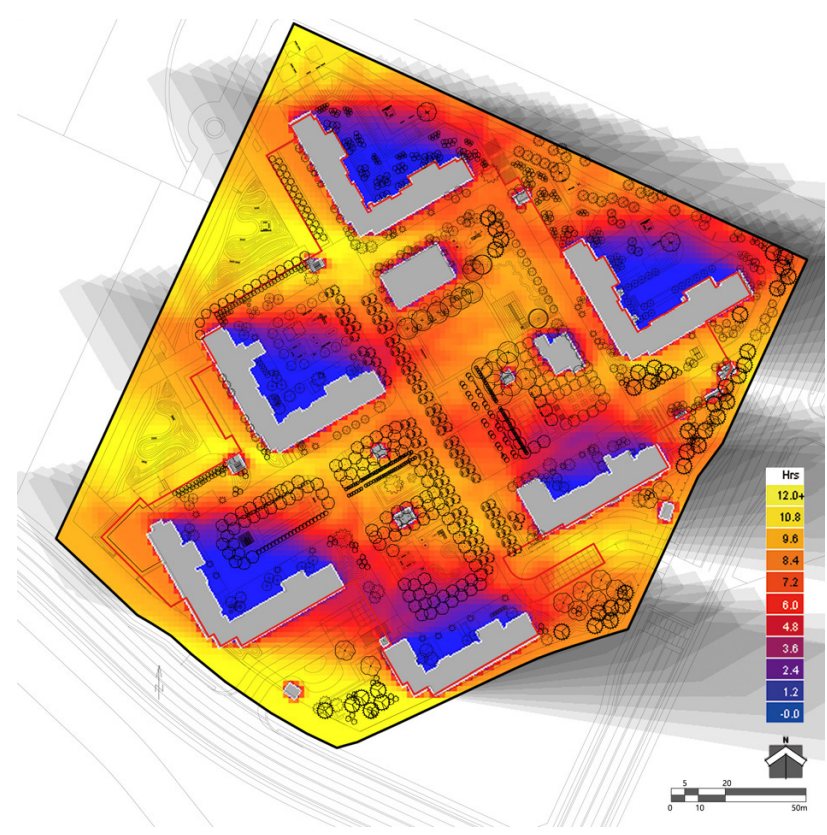

Fig. 5. Study sites daylight simulation.

Table 5. Wind speed distribution of measurement points in study site

\begin{tabular}{|c|c|c|c|c|c|c|c|c|c|c|c|}
\hline \multirow{2}{*}{\multicolumn{2}{|c|}{ Division }} & \multirow[t]{2}{*}{ AWS } & \multicolumn{3}{|c|}{$\begin{array}{l}\text { Outside the site } \\
\text { (SectionI) }\end{array}$} & \multicolumn{3}{|c|}{$\begin{array}{c}\text { Open area inside the site } \\
\text { (Section II) }\end{array}$} & \multicolumn{3}{|c|}{$\begin{array}{c}\text { Shaded area inside the site } \\
\text { (Section III) }\end{array}$} \\
\hline & & & No. 1 & No. 2 & No. 3 & No. 4 & No. 5 & No. 6 & No. 7 & No. 8 & No. 9 \\
\hline \multirow{2}{*}{$\begin{array}{l}\text { Wind speed } \\
\qquad(\mathrm{m} / \mathrm{s})\end{array}$} & March & 2.5 & 2.9 & 2.4 & 2.1 & 2.3 & 2.4 & 1.5 & 1.5 & 1.1 & 0.8 \\
\hline & April & 2.9 & 3.2 & 3.3 & 2.2 & 2.6 & 2.5 & 1.7 & 1.6 & 1.2 & 0.9 \\
\hline
\end{tabular}

Note. AWS $=$ Automatic Weather Station. 


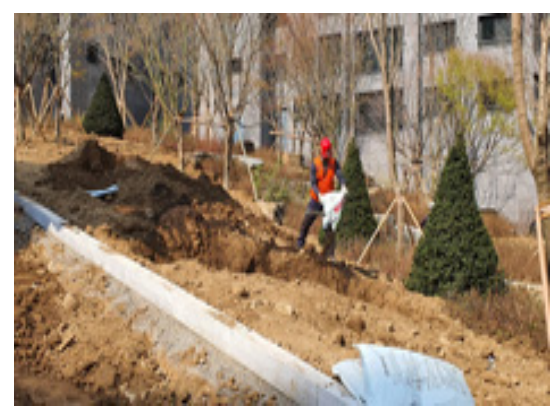

(A) Fertilization

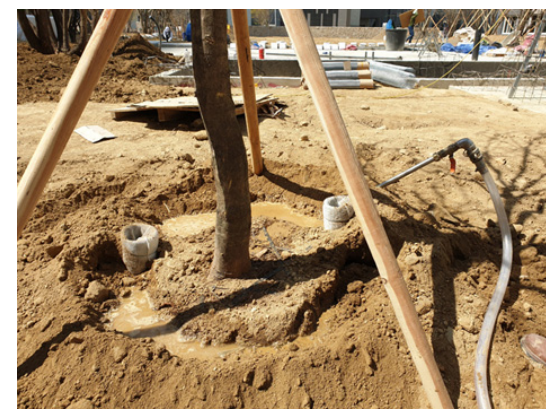

(B) Irrigation

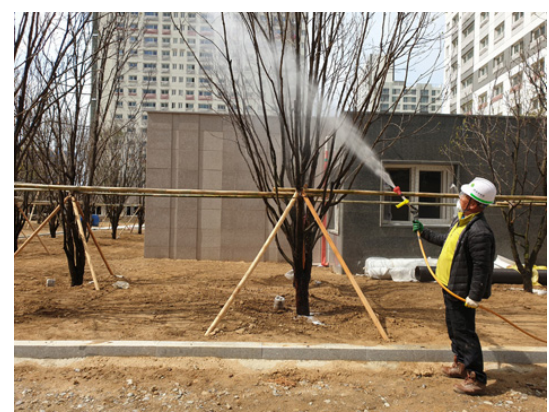

(C) Disease and insect treatment

Fig. 6. Tree maintenance at construction stage.

mixed with rooting compounds and was sprayed right after planting trees when the temperature of soil was $10{ }^{\circ} \mathrm{C}$ or higher and droughts lasted for over 10 days. Decomposed sawdust was sprinkled around the roots as a fertilizer and in the case of Pinus densiflora, pest control was performed after digging trees and pruning their branches (Fig. 6).

\section{Spatial data on trees in study site}

Spatial data on the location of trees planted in the study site were written using AutoCAD 2020 (Fig. 7). When writing spatial data, the size of tree symbols was determined based on the size of their crown measured beforehand, and the management number of trees was given based on the date of planting trees. For a smooth management, number tags were attached to the trees.

\section{Attribute data on trees in study site}

Based on the collected data, attribute data on the tree history management items of trees planted in the study site were written. A total of 286 trees of four evergreen tall-tree species and 1,163 trees of 20 deciduous tall-tree species were planted in the study site, and the number of big tall trees of which root diameter was $30 \mathrm{~cm}$ or higher was 88 , accounting for $6.1 \%$ of the total number of tall trees. The number of trees produced in nurseries located in the southern region was 859 , accounting for $59.3 \%$ of the total number of tall trees and 398 trees were produced in nurseries in the central region, accounting for $27.5 \%$ of the total number of tall trees. The number of trees produced in nurseries located in the central northern region was 192,

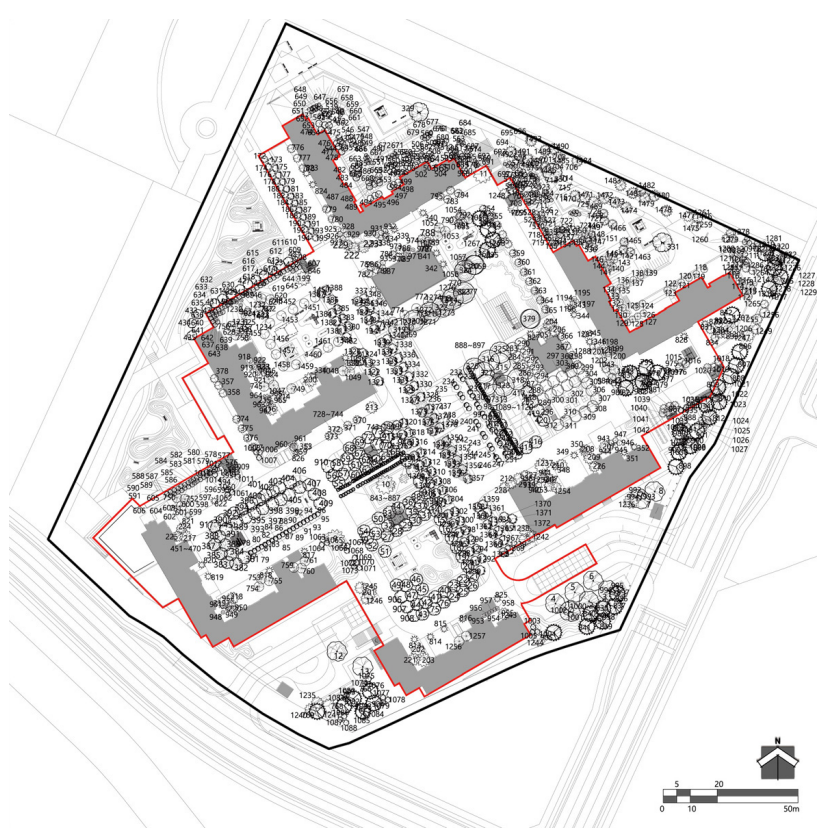

Fig. 7. Spatial information in tree history management system.

accounting for $13.2 \%$ of the total number of tall trees. Most trees were planted on the same day when they were brought into the study site and 148 trees were temporarily planted first, accounting for $10.2 \%$ of the total number of tall trees. The share of trees planted on artificial bases was $77.4 \%$, while that of trees planted on natural bases was $22.6 \%$. Most trees were planted flat on the ground and 66 trees were planted after creating a mounding. The number of trees planted lower was 31 . The number of trees planted in permanently shaded areas that show poor daylight conditions and are less affected by the wind was 411 , accounting for $28.4 \%$ of the total number of tall trees (Table 6). 


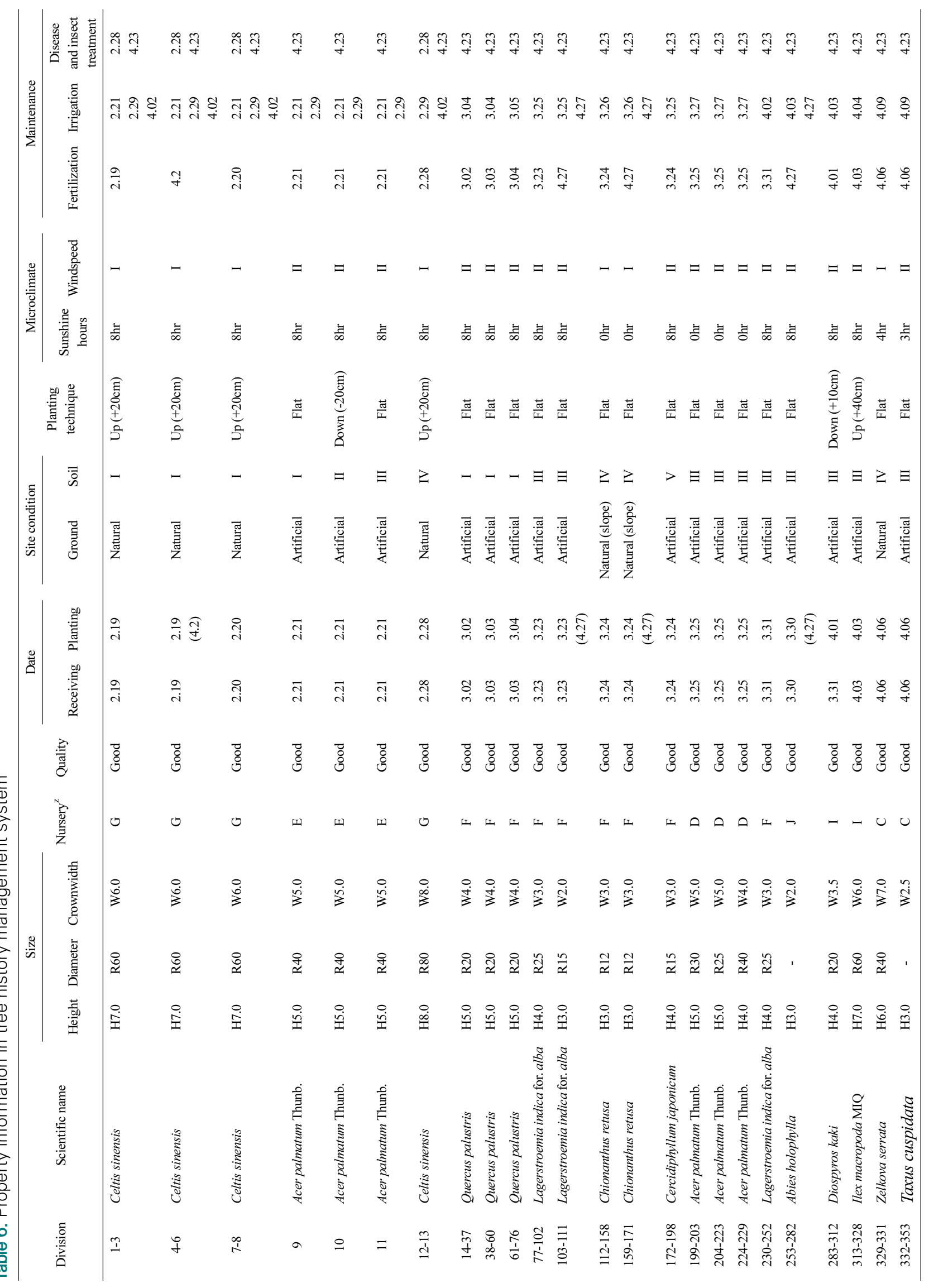




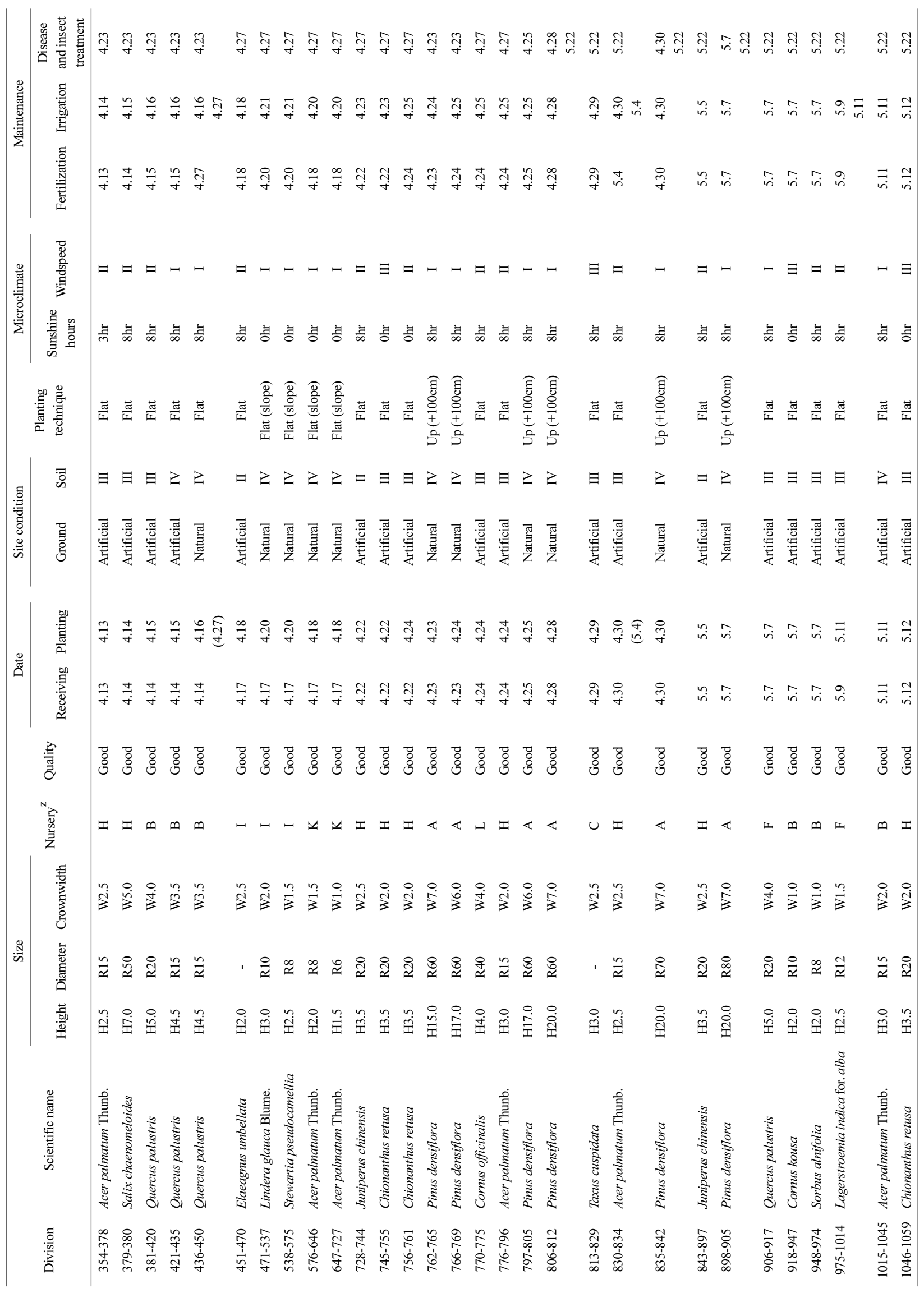




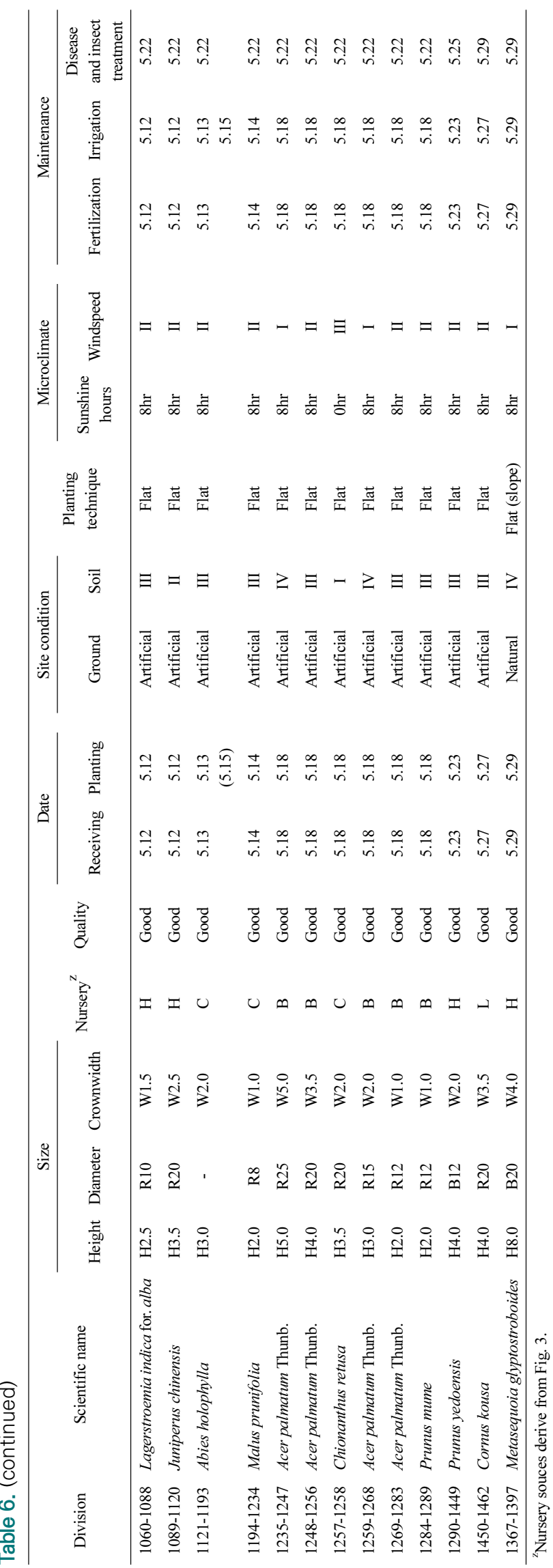

\section{Conclusion}

The purposes of this study are to select tree history management items in the process of planting trees after digging trees in nurseries and transplanting and managing them in a construction site and to suggest detailed data by applying them to the construction site. Through a literature review and a survey on defects in sites where construction was completed, main causes related to tree defects were identified and tree history management items that can be written at the stage of construction were selected and segmented. For an accurate analysis of the cause of tree defects that occur over time, methods and standards of writing detailed items were suggested, and the tree history management items were applied to an actual construction site with the aim of providing base data for analyzing the causes of tree defects.

The main causes of tree defects identified through the literature review and the interview of constructors were divided into design, construction and maintenance stages, and in this study the causes of defects that may occur at the stage of construction were selected as tree history management items. The categorized items according to the causes of defects included the location of nurseries, the date of tree transportation and planting, site conditions, planting techniques, microclimates and maintenance. The location of nurseries provides information on the location of nurseries that produced the trees that were brought into the study site, and the date of tree transportation and planting states when trees were brought into the study site and were planted. When trees were replanted, the status was separately marked. Site conditions state whether trees were planted on natural bases or artificial bases, and divide the study site into five sections according to the types of soil. Planting techniques were divided into up, flat and down planting techniques, and differences between the GL of surrounding green spaces and the diameter of roots were marked. Microclimates provide information on the duration of daylight that was calculated using daylight simulations and the study site was divided into three sections based on the data on wind speed measured at selected points. The items of maintenance include fertilization, watering and pest control and the date of performance was marked. 
Drainage facilities and soil depth were not separately set as they were commonly applied to the study site.

A construction site was selected as a study site and the selected tree history management items were applied to the site. By collecting base data, spatial and attribute data were written for a tree history management system. The study site is located in the central region of Korea where reconstruction projects are actively carried out, and tall trees were planted within the period between March 10 and May 20 suitable for planting. A total of 286 trees of four evergreen tall-tree species and 1,163 trees of 20 deciduous tall-tree species were planted in the study site, and the number of big tall trees of which root diameter was $30 \mathrm{~cm}$ or higher was 88 , accounting for $6.1 \%$ of the total number of tall trees. The number of trees produced in nurseries located in the central northern region was 192, accounting for $13.2 \%$ of the total number of tall trees. Most trees were planted on the same day when they were brought into the study site, and 148 trees were temporarily planted first, accounting for $10.2 \%$ of the total number of tall trees. Most trees were planted flat on the ground, and the number of trees planted lower than the boundary stones as they were planted early was 31 . Their upper part of roots were mostly covered with mulching materials. The number of trees planted in permanently shaded areas that show poor daylight conditions and are less affected by the wind was 411, accounting for $28.4 \%$ of the total number of tall trees.

This study as basic research for the reduction of tree defects observed in apartment complexes is differentiated from earlier studies as this study selected tree history management items for the overall construction process, applied them to an actual construction site and wrote detailed data that can objectively identify the causes of tree defects. However, there are still some limitations. First, history management for maintenance after construction was not included, which may not secure the validity of the identified causes of tree defects. To address the issue, it will be necessary to collect additional data in collaboration with the maintenance office and the constructor of the apartment complex. Second, this study did not include methods of identifying the causes of tree defects by applying the tree history management items. Since defects are gradually observed over the long period of time, it will be necessary to conduct a comprehensive and objective time series analysis on tree defects that occur over time by continuously monitoring and collecting data after construction.

\section{References}

Cho, S.H. 2010. Comparative study on the growth condition of landscape woody plants according to the ground structure of apartment complex. Master's thesis, University of Seoul, Seoul, Korea.

Jung, S.H. and C.B. Sim. 2012. A study on ubiquitous tree management system based on GIS and smartphone for efficiency of arboreal growth management. J. Korea Soc. Comput. Inf. 17(6):119-130. https://doi.org/10.9708/jksc i.2012.17.6.119

Kim, H.S. 2018. A study on the reduction of the landscape tree flaws: Focusing on Gwangju Metropolitan City park and green Area. Master's thesis, Chonnam University, Gwangju, Korea.

Kim, J.P., Y.S. Kim, and D.J. Kim. 2007. A study on the computerization plan of tree management in landscape architecture at university campus. J. Korean Inst. Educ. Facil. 14(2):5-15.

Kim, W.S. 2014. A study on the tendency of planting tree defects according to the changes of landscape in apartment. Master's thesis, Hanyang University, Seoul, Korea.

Kim, Y.H. 2006. A study on the status of defect of landscape trees its improvement: With a special reference to the landscape planting works at the apartment in Seoul. Master's thesis, Korea University, Seoul, Korea.

Lee, S.B. 2004. Landscape architecture engineering (p.421). Seoul, Korea: Munundang Publishing.

Lim, W.H. and Y.S. Kim. 2001. Defects of planting in landscape plants in apartment complex. J. Korean Inst. Landsc. Archit. 29(2):61-67.

Ministry of Land, Infrastructure and Transport. 2016. Landscape architecture standard specification(p. 86). Sejong, Korea. Author.

Park, S.W. 2019. The improvement of thermal environment in exterior spaces of the apartment site through landscape engineering field measurement during summer 
season. Doctoral dissertation, Yeungnam University, Gyeongsan, Korea.

Yoon, E.J., E.Y. Lee, M.N. Kim, S.B. Oh, and Y.J. Lee.
2017. A preliminary study on the planting condition improvement by climate changes (pp. 115-130). Daejeon, Korea: Land and Housing Institute. 